\title{
Evaluation of the efficacy of flecainide acetate in the treatment of ventricular premature contractions
}

\author{
Khulood A. Muhiddin ${ }^{1}$, P. Turner ${ }^{1}$, K. Hellestrand ${ }^{2}$ and A.J. Camm ${ }^{2}$ \\ Departments of ${ }^{1}$ Clinical Pharmacology, and ${ }^{2}$ Cardiology, St Bartholomew's Hospital, London, EC1, UK.
}

\begin{abstract}
Summary: The efficacy of flecainide acetate in suppressing ventricular premature contractions in 14 patients was evaluated in a double-blind, cross- over, placebo controlled, randomized and balanced study. Each treatment period was 2 weeks followed by a 3-4d placebo washout period and the study lasted 5 weeks. Flecainide was given in a dose of $200 \mathrm{mg}$ twice daily.

A significant reduction in the total number of $Q R S$ complexes in a $24 \mathrm{~h}$ period was observed during the active compared with placebo treatment $(P<0.05)$. In comparison with placebo, flecainide reduced the number of aberrant and premature aberrant $Q R S$ complexes $(P<0.01)$. The mean suppression rate of aberrant QRS complexes during flecainide treatment was $85.4 \%$ and that of premature aberrant complexes was $93.2 \%$. Maximum heart rate measured by $24 \mathrm{~h}$ ECG decreased significantly during flecainide therapy $(P<0.01)$, although no change occurred with resting heart rate measured clinically or by ECG. Severe dizziness associated with flecainide therapy necessitated withdrawal of 2 patients from the study. A proarrhythmic effect of flecainide, ventricular tachycardia, was observed in one patient.
\end{abstract}

\section{Introduction}

Flecainide acetate is a recently introduced Class 1 antiarrhythmic compound (Banitt et al., 1977; Cowan \& Vaughan Williams, 1981). Flecainide has several favourable pharmokinetic properties which include almost complete oral absorption, minimal first pass metabolism and a relatively long elimination half-life of 7-22 h (mean 14 h) (Conard et al., 1979).

Several animal studies showed that flecainide suppresses experimentally induced ventricular arrhythmias in dogs, mice (Schmid et al., 1975) and pigs (Verdouw et al., 1979). Evaluation of the antiarrhythmic efficacy of flecainide in open studies in patients showed marked suppression of ventricular premature contractions (VPCs) (Hoback et al., 1978; Bender et al., 1979; Somani, 1980).

This study was designed to assess the value of oral flecainide in suppressing frequent VPCs. The effectiveness of flecainide in controlling supraventricular arrhythmias and repetitive VPCs, including couplets, salvos and non-sustained ventricular tachycardia, was also evaluated. The adverse effects of flecainide were also noted, including a proarrhythmic effect which was mentioned in a previous publication (Muhiddin $e t$ al., 1982). Haematological and biochemical variables

Correspondence: K.A. Muhiddin, M.B., Ch.B. Ph.D., Department of Clinical Pharmacology, St. Bartholomew's Hospital, West Smithfield, London, EC1A 7BE, UK.

Accepted: 29 January 1985 were monitored during the study to assess the safety of flecainide.

\section{Methods}

Patients

Fifteen non-hospitalized patients with frequent VPCs participated in the study. The patients were 7 males and 7 (non-pregnant) females, aged between 30-72y and weighing $54-90 \mathrm{~kg}$. The patients chosen fulfilled the following criteria: (a) having chronic stable VPCs with an average of more than 500 VPCs (aberrant $\mathrm{QRS}$ complexes) in $24 \mathrm{~h}$ as documented by each of the three preliminary $24 \mathrm{~h}$ ambulatory electrocardiograms (24 h ECG); (b) free from other antiarrhythmic therapy for at least 2 weeks prior to the study; (c) absence of heart failure; (d) absence of second degree or greater AV block, bundle branch block or distal block; (e) no history of myocardial infarction within 6 weeks before entry to the study; (f) absence of clinically significant endocrine, haematological, gastrointestinal, hepatic or renal abnormalities.

\section{Design and protocol of the study}

The study was double-blind, cross-over, placebo controlled, randomized and balanced. It was carried out 
Day numbers

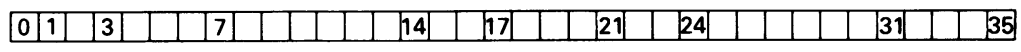

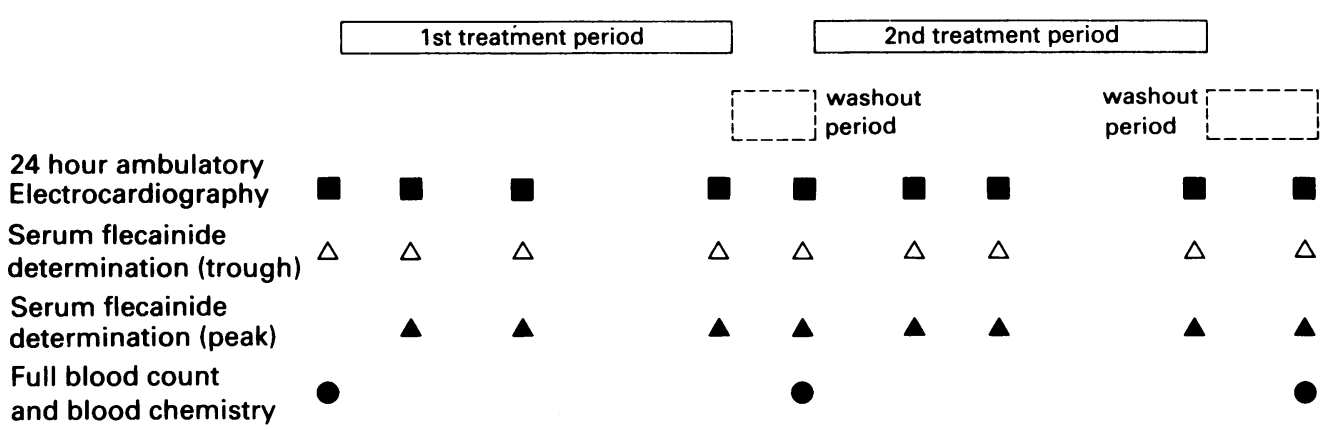

Figure 1 Design of the study.

over 5 weeks. A 3-4 d placebo washout period followed each treatment session of 2 weeks (Figure 1).

On day 0 of the study the following were performed: (a) medical history including detailed cardiovascular history; (b) complete physical examination including measuring radial pulse rate and arterial blood pressure using ordinary mercury sphygmomanometer; (c) haematological and biochemical screening tests and estimation of serum flecainide concentration (baseline) using the gas liquid chromatographic method; (d) $24 \mathrm{~h}$ ECG.

Patients began taking their medication after completion of the first $24 \mathrm{~h}$ ECG on the initial visit (day 0 ). Further $24 \mathrm{~h}$ ECG recordings were performed on the 3rd, 7th, 14th, 17th, 21st, 24th, 31st and 35th days. In other words, there were three $24 \mathrm{~h}$ ECGs during each treatment period, 1 during each placebo washout period and 1 on day 0 . On each of the above mentioned visits the following were also carried out: (a) interval medical history and adverse effects enquiry by volunteering any symptoms; (b) complete physical examination; (c) determination of trough and peak serum concentrations of flecainide. The haematological and biochemical tests were repeated on days 17 and 35 of the trial, i.e. 3-4 d after each treatment period.

\section{Drugs and dosages}

Flecainide was administered in a dose of $200 \mathrm{mg}$ twice daily at $12 \mathrm{~h}$ intervals.

\section{Arrhythmia recording and analysis of $24 \mathrm{~h}$ ambulatory ECG}

Twenty four $\mathrm{h}$ ambulatory ECG recordings were carried out using Oxford Medical Systems Series 4-24/ 2 twin channel cassette tape recorders. They were analysed by a high speed analyser (Pathfinder-I Revnold Medical Electronics), and the minimum and maximum heart rates and numbers of normal and abnormal complexes/h recorded (Muhiddin, 1983).

\section{Quality control}

Some non-selected $24 \mathrm{~h}$ ambulatory ECG recordings, which were obtained from patients who participated in this study were analysed at another centre using the same type of analyser. Good agreement between centres was demonstrated, e.g., for total aberrant QRS complexes the correlation coefficient was 0.98 , with a slope of 1.06 and intercept of $361(n=74)$.

\section{Statistical analysis}

Statistical analysis and calculations of the median were applied to all patients who received both the active and placebo treatments. Patients 4,7,9 and 11 were therefore not included (see later). Statistical analysis was applied to compare the mean values of all visits during each treatment period for each individual patient. To assess the significance of changes after flecainide in comparison with placebo, Student's paired $t$-test was applied to minimum and maximum heart rate, systolic and diastolic blood pressure and pulse rate. The Wilcoxon signed rank test on matched pairs was used for the rest of the variables. The percentage change was calculated for each individual patient in respect of the aberrant and premature aberrant QRS complexes. The comparison was made between the mean values during placebo and flecainide treatment for each patient. Since patient 9 and 11 did not receive placebo treatment (withdrawn from the study, see later), their baseline values were taken into account instead. 


\section{Results}

\section{Control observations}

Summary of the patients who participated in the study is given in Table I. The patients studied were either inadequately controlled with other antiarrhythmic drugs or experienced intolerable adverse effects.

\section{Patient withdrawal}

Four patients were withdrawn from the study because of long attacks of supraventricular tachycardia while on placebo (patient 4), and severe dizziness associated with flecainide therapy (patients 9 and 11). Patient 7 decided not to continue the trial because of his job.

Table I Summary of the patients who participated in the study

\begin{tabular}{|c|c|c|c|c|c|}
\hline $\begin{array}{l}\text { Patient } \\
\text { No. }\end{array}$ & $\begin{array}{l}\text { Age/ } \\
\text { sex }\end{array}$ & $\begin{array}{l}\text { Cardiac } \\
\text { diagnosis }\end{array}$ & Arrhythmias & Symptoms & $\begin{array}{l}\text { Previous } \\
\text { antiarrhythmic }\end{array}$ \\
\hline 1 & $30 / \mathrm{F}$ & $\begin{array}{l}\text { No known } \\
\text { OHD }\end{array}$ & $\begin{array}{l}\text { Unimorph. VPCs, } \\
\text { bigemini, } \\
\text { trigemini }\end{array}$ & Dizziness & $\begin{array}{l}\text { Disopyramide, } \\
\text { mexiletine }\end{array}$ \\
\hline 2 & $61 / \mathrm{M}$ & CAD & $\begin{array}{l}\text { Unimorph. VPCs, } \\
\text { bigemini, } \\
\text { couplets, VT }\end{array}$ & Palpitation & $\begin{array}{l}\text { Disopyramide, } \\
\text { mexiletine }\end{array}$ \\
\hline 3 & $51 / \mathrm{M}$ & CAD & $\begin{array}{l}\text { Unimorph. VPCs, } \\
\text { bigemini, } \\
\text { couplets }\end{array}$ & Palpitation & None, ${ }^{*}$ \\
\hline 4 & $45 / F$ & $\begin{array}{l}\text { Dual AV } \\
\text { nodal } \\
\text { pathway }\end{array}$ & $\begin{array}{l}\text { Multimorph. VPCs, } \\
\text { APCs, SVT }\end{array}$ & Palpitation & $\begin{array}{l}\text { Amiodarone, } \\
\text { disopyramide, } \\
\text { mexiletine }\end{array}$ \\
\hline 5 & $71 / \mathrm{F}$ & $\begin{array}{l}\text { No known } \\
\text { OHD }\end{array}$ & $\begin{array}{l}\text { Multimorph. VPCs, } \\
\text { bigemini, } \\
\text { couplets }\end{array}$ & None & None \\
\hline 6 & $48 / F$ & MVP & $\begin{array}{l}\text { Multimorph. VPCs, } \\
\text { bigemini, } \\
\text { couplets }\end{array}$ & Palpitation, & None \\
\hline 7 & $58 / \mathrm{M}$ & $\begin{array}{l}\text { No known } \\
\text { OHD }\end{array}$ & $\begin{array}{l}\text { Unimorph. VPCs, } \\
\text { bigemini, } \\
\text { couplets }\end{array}$ & $\begin{array}{l}\text { Dizziness, } \\
\text { palpitation }\end{array}$ & Disopyramide \\
\hline 8 & $72 / \mathrm{M}$ & $\begin{array}{l}\text { No known } \\
\text { OHD }\end{array}$ & $\begin{array}{l}\text { Multimorph. VPCs, } \\
\text { bigemini, } \\
\text { couplets, } \\
\text { salvos, APCs }\end{array}$ & None & None \\
\hline 9 & $51 / \mathrm{F}$ & $\begin{array}{l}\text { No known } \\
\text { OHD }\end{array}$ & $\begin{array}{l}\text { Unimorph. VPCs } \\
\text { couplets, } \\
\text { trigemini, } \\
\text { quadrigemini }\end{array}$ & Palpitation & None \\
\hline 10 & $68 / M$ & CAD & $\begin{array}{l}\text { Multimorph. VPCs, } \\
\text { couplets, } \\
\text { trigemini }\end{array}$ & None & Disopyramide \\
\hline 11 & $46 / F$ & $\begin{array}{l}\text { No known } \\
\text { OHD }\end{array}$ & Unimorph. VPCs, & Palpitation & Disopyramide \\
\hline 12 & $44 / F$ & $\begin{array}{l}\text { No known } \\
\text { OHD }\end{array}$ & Unimorph. VPCs, & $\begin{array}{l}\text { Palpitation, } \\
\text { chest pain, } \\
\text { dizziness }\end{array}$ & None \\
\hline 13 & $64 / \mathrm{M}$ & CAD & $\begin{array}{l}\text { Multimorph. VPCs, } \\
\text { couplets }\end{array}$ & None & Mexiletine \\
\hline 14 & $54 / \mathrm{M}$ & $\begin{array}{l}\text { No known } \\
\text { OHD }\end{array}$ & $\begin{array}{l}\text { Unimorph. VPCs, } \\
\text { bigemini } \\
\text { trigemini }\end{array}$ & $\begin{array}{l}\text { Dizziness, } \\
\text { palpitation }\end{array}$ & Disopyramide \\
\hline
\end{tabular}

F: female; M: male; CAD: coronary artery disease; OHD: organic heart disease; AV: atrioventricular; SVT: supraventricular tachycardia; MVP: mitral valve prolapse; APC: atrial premature contractions; VT: ventricular tachycardia.

*Patient 3 was on diazepam, theophylline and salbutamol concomitantly. 


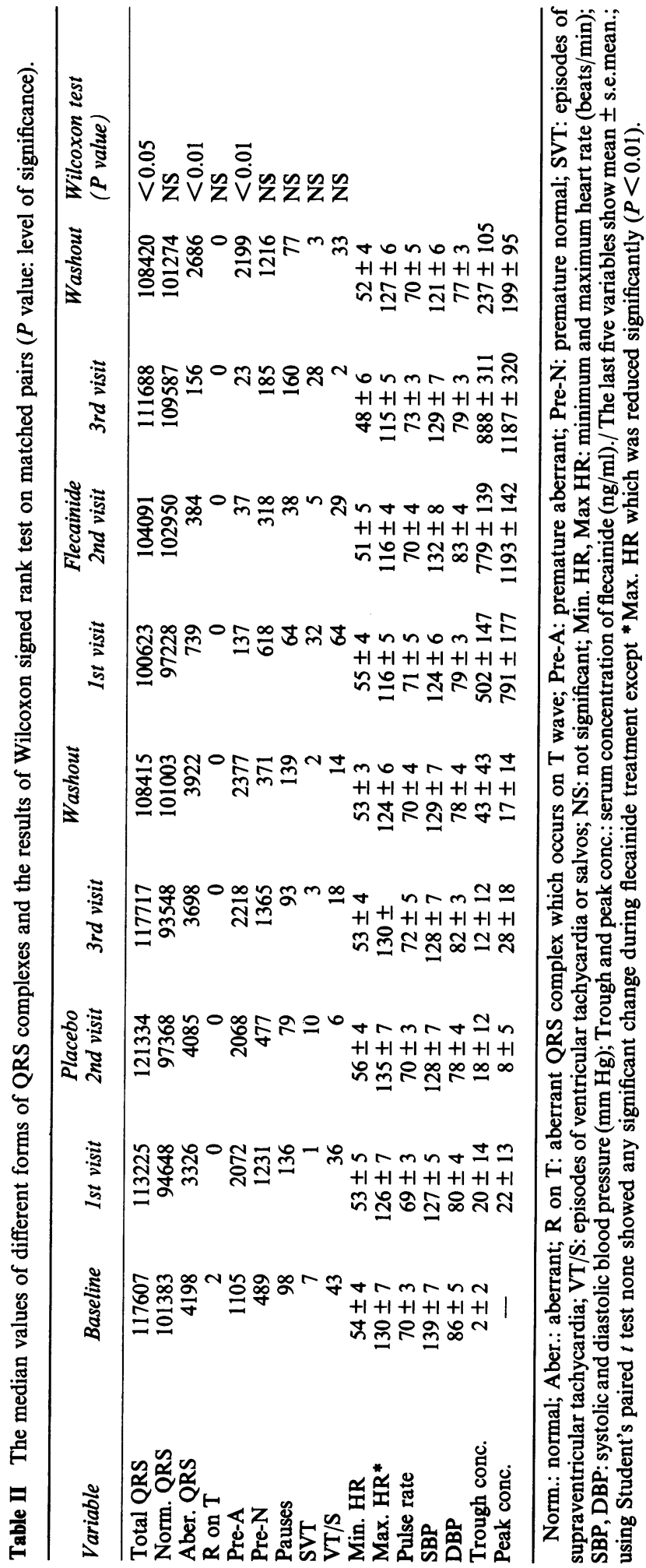




\section{Twenty four $h E C G$}

Median values and results of statistical analysis are given in Table II.

A significant reduction in the total number of QRS complexes in a $24 \mathrm{~h}$ period was observed during the active compared with placebo treatment $(P<0.05)$. In comparison with placebo, flecainide reduced the number of aberrant and premature aberrant QRS complexes $(P<0.01)$, which was associated with improvement of symptoms. The percentage reduction in aberrant QRS complexes was $85.4 \pm 4.3 \%$ (mean\pm s.e.m.) and in premature aberrant complexes was $93.2 \pm 2.3 \%$ (Table III). Flecainide did not change significantly the number of $R$ on $T$ pauses and runs of supraventricular tachycardia (SVT)/24 h. The total number of episodes of ventricular tachycardia or salvos (which included couplets or more; VT/S) in $24 \mathrm{~h}$ was not reduced significantly. Out of 10 patients included in the interpretation of the results, seven had a lower incidence of VT/S during flecainide treatment, while two had a higher incidence and one patient did not have this arrhythmia during either treatment.

Minimum heart rate did not change significantly with flecainide therapy. Maximum heart rate decreased in all 10 patients, the mean values ranged

Table III Percentage change in the total aberrant and premature aberrant QRS complexes. The comparison was made between the mean values during flecainide and placebo treatments.

\begin{tabular}{lcc}
\hline $\begin{array}{l}\text { Patient } \\
\text { number }\end{array}$ & $\begin{array}{c}\text { Percentage } \\
\text { change in } \\
\text { aberrant } Q R S\end{array}$ & $\begin{array}{c}\text { Percentage change } \\
\text { in premature } \\
\text { aberrant } Q R S\end{array}$ \\
\hline 1 & $-83.9 \%$ & $-95.2 \%$ \\
2 & $-74.6 \%$ & $-89.4 \%$ \\
3 & $-92.9 \%$ & $-76.1 \%$ \\
4 & - & $-97.2 \%$ \\
5 & $-91.3 \%$ & $-92.8 \%$ \\
6 & $-79.9 \%$ & $-89.1 \%$ \\
7 & - & $-99.95 \%$ \\
8 & $-58.9 \%$ & $-94.1 \%$ \\
$9 *$ & $-99.4 \%$ & $-98.1 \%$ \\
10 & $-74.1 \%$ & $-98.9 \%$ \\
$11 *$ & $-87.7 \%$ & $-99.2 \%$ \\
12 & $-98.3 \%$ & $-100.0 \%$ \\
13 & $-99.7 \%$ & $-93.2 \pm 2.3 \%$ \\
14 & $-100.0 \%$ & \\
Mean \pm s.e.mean & $-85.4 \pm 4.3 \%$ & \\
(excluding & & \\
patients 9 & & \\
and 11) & & \\
\hline
\end{tabular}

* = comparison was made in relation to the baseline values). See text for further details. between $126-135$ beats/min during the 3 visits whilst on the placebo course, compared with 115-116 beats/ min during the visits on flecainide therapy $(P<0.01)$.

\section{Pulse rate and blood pressure}

Neither radial pulse rate (measured clinically) nor blood pressure (systolic and diastolic) changed significantly during flecainide therapy in comparison with placebo (Tables II and III).

\section{Serum concentration of flecainide}

During the flecainide treatment period, mean trough concentrations of flecainide were 502,779 and $888 \mathrm{ng} /$ $\mathrm{ml}$ over the three visits, while mean peak concentrations were 791,1193 and $1187 \mathrm{ng} / \mathrm{ml}$, respectively.

\section{Haematology and biochemistry}

Haematological and biochemical screening tests did not manifest any abnormality after 2 weeks of flecainide therapy.

\section{Adverse effects}

All patients investigated had adverse effects during flecainide therapy varying from mild to moderate and severe (Table IV). Patient 6 complained of dizziness after receiving the second dose of flecainide. However, her physical examination in the first visit during the flecainide course revealed no indication for discontinuation of the study. The $24 \mathrm{~h}$ ECG recording, for that visit, showed three episodes of ventricular tachycardia, associated with dizziness, lasting up to $30 \mathrm{~s}$ at a rate of 130-165 beats/min (Figure 2). On the day of this recording the trough serum concentration of flecainide was $714 \mathrm{ng} / \mathrm{ml}$ and the peak concentration was $1183 \mathrm{ng} / \mathrm{ml}$. The QRS duration increased from 100 milliseconds (ms), before flecainide, to $140 \mathrm{~ms}$, during flecainide treatment. The QT interval prolonged from $420 \mathrm{~ms}$ to $480 \mathrm{~ms}$, the QTc (QT/R-R (s) $\left.{ }^{1 / 2}\right)$ increased from $449 \mathrm{~ms}$ to $524 \mathrm{~ms}$, the JT interval (QT minus QRS) prolonged from $320 \mathrm{~ms}$ to $340 \mathrm{~ms}$ and JTc (QTc minus QRS) prolonged from $349 \mathrm{~ms}$ to $384 \mathrm{~ms}$. Flecainide was discontinued and no further episode of ventricular tachycardia was documented.

The most frequent adverse effects were dizziness, blurred vision and nausea. Severe dizziness was the reason to withdraw patients 9 and 11 from the study. Blurred vision, which was transient and occurred usually between 2 and $4 \mathrm{~h}$ after the tablet ingestion, did not require withdrawal from the study. Among the adverse effects reported in the study during flecainide therapy were headache (4 patients), chest pain (3 patients), lethargy ( 2 patients) and numbness of the lips ( 2 patients). One patient complained of involun- 
Table IV Efficacy of flecainide in suppressing ventricular premature contractions. Summary of the adverse effects (according to their frequency) experienced by the patients who participated in the study. Numbers indicating individual patient numbers in the study $(n=14)$.

\begin{tabular}{lcc}
\hline Adverse effects & Flecainide & Placebo \\
\hline Dizziness & 9 & 2 \\
Blurred vision & 7 & 3 \\
Nausea & 6 & 1 \\
Light headedness & 4 & \\
Headache & 4 & 2 \\
Chest pain & 3 & 2 \\
Involuntary movement of the right & 1 & \\
$\quad$ hand & & \\
Lethargy & 2 & 1 \\
Numbness of the lips & 2 & \\
Palpitation & 2 & 5 \\
Deterioration of the visual acuity & 1 & \\
Photophobia & 1 & \\
Eye ache & 1 & \\
Abdominal discomfort & 1 & \\
Epigastric pain & 1 & 1 \\
Unpleasant taste and smell & 1 & \\
Vomiting & 1 & \\
Lack of concentration & 1 & \\
Nervousness & \\
Pain in the right arm & 1 & 1 \\
Dry mouth & 1 & \\
Itching & 1 & 2 \\
Shortness of breath & 1 & \\
\hline
\end{tabular}

tary movements in his right hand and an unpleasant taste and smell associated with flecainide treatment.

\section{Discussion}

\section{Efficacy against ventricular arrhythmias}

In this study, flecainide significantly reduced the frequency of aberrant and premature aberrant QRS complexes. The reduction seemed to be a genuine drug effect rather than due to naturally occurring spontaneous variability of VPC count between days (Morganroth et al., 1978). This is particularly likely because of the increase in the frequency of most arrhythmias during the washout period following treatment with flecainide. Furthermore, Morganroth and co-workers (1978) postulated that when comparison is made between three $24 \mathrm{~h}$ control monitoring sessions and three $24 \mathrm{~h}$ periods of drug test monitoring, a reduction of greater than $65 \%$ in mean hourly VPC count is necessary to imply that the suppression is due to the drug's action. The percentage reduction achieved in this study was much higher than the limit set by these authors. These results are similar to those obtained by other investigators who found between 90 and $100 \%$ suppression in the frequency of VPCs during flecain ide therapy (Anderson et al., 1981; Duff et al., 1981 Granrud et al., 1981; Bluschke et al., 1982; Duran es al., 1982; Hodges et al., 1982; Klempt et al., 19820. Abitbol et al., 1983; Salerno et al., 1983). In this study;

a Sinus rhythm

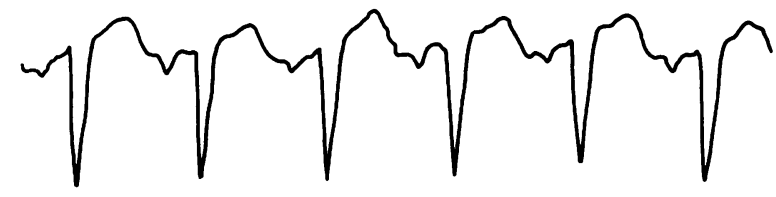

b Ventricular tachycardia

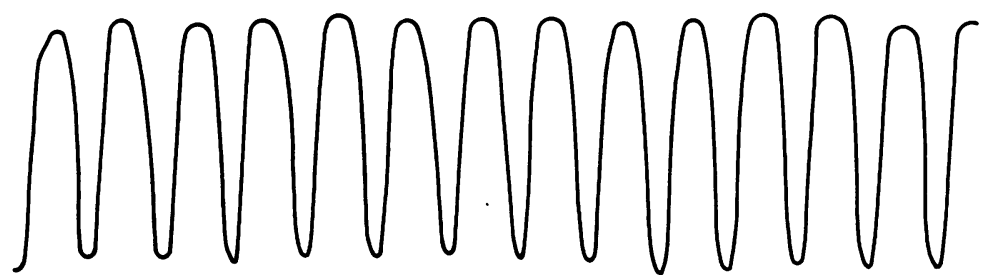

Figure 2 Ventricular tachycardia (VT) associated with flecainide therapy in patient 6 . First strip shows sinus rhythm before the VT episode which is presented in the second strip. 
flecainide reduced the number of episodes of VT/S (repetitive VPCs) in 7 out of 10 patients but this did not reach statistical significance. In other reports there has been a reduction or elimination of repetitive VPCs by an average of 90-100\% (Anderson et al., 1981; Duff et al., 1981; Duran et al., 1982; Hodges et al., 1982; Salerno et al., 1983). Furthermore, it has been shown that oral flecainide is more effective than mexiletine (Klempt et al., 1982), quinidine (Morganroth et al., 1983; Salerno et al., 1983) and disopyramide (Kjekshus et al., 1984) in suppressing total VPCs and repetitive VPCs.

\section{Efficacy against supraventricular arrhythmias}

Flecainide was not effective in reducing the frequency of premature normal QRS complexes and SVT. However, Clementy and colleagues (1982) demonstrated that flecainide was as effective as quinidine in reducing atrial premature contractions.

\section{Effect on heart rate}

In this study, flecainide produced a significant reduction in the maximum heart rate which could be due to a significant reduction in the frequency of VPCs. Heart rate tends to increase in the presence of frequent VPCs due to inefficient contractions. With the suppression of VPCs and the appearance of normal QRS complexes and normal contractions heart rate may consequently fall. Duran et al. (1982) have also reported a small decrease in the average heart rate over $24 \mathrm{~h}$ in a similar study.

\section{Adverse effects}

Patient 6 was withdrawn from the study due to the occurrence of ventricular tachycardia. Since ventricular tachycardia was not documented before the commencement or after discontinuation of flecainide therapy, and in view of high serum concentration at the time of ventricular tachycardia, it is probable that flecainide toxicity was responsible. Sinus rhythm ECG during flecainide therapy showed lengthening of QT, QTc intervals and QRS duration with lesser change in JT or JTc interval. Other studies also showed that oral flecainide markedly impairs intra-ventricular conduction, produces a widening of QRS complex, corresponding $\mathrm{QT}$ prolongation and no change in JT interval (Duran et al., 1982) or little effect on JTc (Salerno et al., 1983). In this case symptomatic episodes of ventricular tachycardia developing in association with these ECG changes suggest that this arrhythmia was related to slowing of conduction. This complication is probably dose related. Winkle et al. (1981) reported similar arrhythmias associated with encainide therapy, which they suggest could be due to a similar mechanism. Single cases of ventricular tachycardia, not of the 'torsade de pointes' type, associated with QTc prolongation induced by flecainide were reported by Lui et al. (1982) and Hohnloser $e t$ al. (1983). Nathan et al. (1983) reported 6 other cases of cardiac arrhythmias associated with flecainide treatment.

Several other adverse effects were noted with flecainide treatment (Table 4). Dizziness was a frequent complaint (in 9 patients) which was not associated with frequent VPCs or any other arrhythmia when the patients were receiving flecainide except in patient 6. In spite of high serum flecainide concentrations in 5 patients, none of them had serious adverse effects that necessitated stopping the medication. In this study, blurred vision was a common adverse effect, reported by 7 patients. It might be considered as an anticholinergic adverse effect of flecainide; however, no other anticholinergic effects, such as urinary retention or hesitancy, were notified in the study. Dry mouth was reported by one patient but this occurred during both active and placebo treatments. Other investigators have also reported dryness of the mouth among the adverse effects of intravenous flecainide in an open study (Abitbol et al., 1983). Although these adverse effects could be related to anticholinergic activity, flecainide did not produce anticholinergic effects in guinea pigs (Riker Laboratories, data on file). In addition, previous results (Muhiddin \& Turner, 1983) have shown that intravenous flecainide, in a double-blind study, did not produce a significant effect in respect of dry mouth in normal healthy volunteers. The high incidence of adverse effects in this study may be partly due to associated high serum concentrations of flecainide observed in this group of patients.

After 2 weeks of flecainide therapy no obvious changes from baseline were noted in any haematological or biochemical variable. However, longer periods of monitoring would appear prudent.

In summary, this study showed that flecainide was more effective in controlling ventricular than supraventricular arrhythmias. This was associated with improvement of symptoms. Flecainide therapy is not free from risk of development of serious arrhythmias. Several other adverse effects, varying between mild to severe, were also noted with flecainide treatment. Since the aim of antiarrhythmic therapy is not only the elimination of arrhythmias, but also an improvement in prognosis, the value of flecainide in the management of patients at risk of sudden cardiac death remains to be seen.

\section{Acknowledgements}

We thank Riker Laboratories, Loughborough, U.K. for supplying flecainide and matching placebo tablets. 


\section{References}

ABITBOL, H., CALIFANO, J.E., ABATE, C., BEILIS, P. \& CASTELLANOS, H. (1983). Use of flecainide acetate in the treatment of premature ventricular contractions. American Heart Journal, 105, 227.

ANDERSON, J.L., STEWART, J.R., PERRY, B.A., VAN HAMERSVELD, D.D., JOHNSON, T.A., CONARD, G.J., CHANG, S.F., KVAM, D.C. \& PITT, B. (1981). Oral flecainide acetate for the treatment of ventricular arrhythmias. New England Journal of Medicine, 305, 473.

BANITT, E.H., BRONN, W.R., COYNE, W.E. \& SCHMID, J.R. (1977). Antiarrhythmics. 2. Synthesis and antiarrhythmic activity of $\mathrm{N}$-(piperidylalkyl) trifluoroethoxybenzamides. Journal of Medicinal Chemistry, 20, 821.

BENDER, F., BRISSE, B., CRONHEIM, G., DOBBELER, R., GULKER, H. \& BRAMANN, H.U. (1979). Extrasystoliehandlung mit flecainid. Zeitschrift fur Kardiologie, 68, 280.

BLUSCHKE, V., BREITHARDT, G., ABENDROTH, R.R. \& SEIPEL, L. (1982). Effect of flecainide on chronic ventricular arrhythmias. Zeitschrift fur Kardiologie, 71, 284.

CLEMENTY, J., FALQUIER, J.F., DALLOCCHIO, M. \& BRICAUD, H. (1982). Etude comparée de l'activité d'une quinidine retard et de la flecainide dans le traitement des extrasystoles. Médecine et Hygiène, 40, 4353.

CONARD, G.J., CARLSON, G.L., FROST, J.W. \& OBER, R.E. (1979). Human plasma pharmacokinetics of flecainide acetate (R-818), a new antiarrhythmic, following single oral and intravenous doses. Clinical Pharmacology and Therapeutics, 25, 218.

COWAN, J.C. \& VAUGHAN WILLIAMS, E.M. (1981). Characterization of a new oral antiarrhythmic drug, flecainide (R818). European Journal of Pharmacology, 73, 333.

DUFF, H.J., RODEN, D.M., MAFFUCCI, R.J., VESPER, B.S., CONARD, G.J., HIGGINS, S.B., OATES, J.A., SMITH, R.F. \& WOOSLEY, R.L. (1981). Suppression of resistant ventricular arrhythmias by twice daily dosing with flecainide. American Journal of Cardiology, 48, 1133.

DURAN, D., PLATIA, E.V., GRIFFITH, L.S.C., ADHAR, G. \& REID, P.R. (1982). Suppression of complex ventricular arrhythmias by oral flecainide. Clinical Pharmacology and Therapeutics, 32, 554.

GRANRUD, G., KREJEL, J., COYNE, T. \& HODGES, M. (1981). Sustained elimination of ventricular arrhythmias during chronic flecainide dosing. Circulation, 64, suppl. IV, 316.

HOBACK, J., HODGES, M., FRANCIS, G.S., SHARMA, B. \& ASINGER, R.W. (1978). Flecainide (R-818), a new antiarrhythmic agent: effects on ventricular premature beats. Circulation, 58, suppl. II, 246.

HODGES, M., HAUGLAND, J.M., GRANRUD, G., CONARD, G.J., ASINGER, R.W., MIKELL, F.L. \& KREJCI, J. (1982) Suppression of ventricular ectopic depolarizations by flecainide acetate, a new antiarrhythmic agent. Circulation, $65,879$.

HOHNLOSER, S., ZEIHER, A., HUST, M.H., WOLLSCHLAGER, H. \& HUST, H. (1983). Flecainide-induced aggravation of ventricular tachycardia. Clinical Cardiology, 6, 130.

KJEKSHUS, J., BATHEN, J., ORNING, O.M. \& STORSTEIN, L. (1984). A double-blind, crossover comparison of flecainide acetate and disopyramide phosphate in the treatment of ventricular premature complexes. American Journal of Cardiology, 53, 72B.

KLEMPT, H.W., NAYEBAGHA, A. \& FABRY, E. (1982). Antiarrhythmic efficacy of mexiletine, propafenone and flecainide in ventricular premature beats. A comparative study in patients after myocardial infarction. Zeitschrift fur Kardiologie, 71, 340.

LUI, H.K., LEE, G., DIETRICH, P., LOW, R.I. \& MASON, D.T. (1982). Flecainide-induced QT prolongation and ventricular tachycardia. American Heart Journal, 103, 567.

MORGANROTH, J. \& The Flecainide - Quinidine Research Group (1983). Flecainide versus quinidine for treatment of chronic ventricular arrhythmias. A multicenter clinical trial. Circulation, 67, 1117.

MORGANROTH, J., MICHELSON, E.L., HOROWITZ, L.N., JOSEPHSON, M.E., PEARLMAN, A.S. \& DUNKMAN, W.B (1978). Limitations of routine long-term electrocardiographic monitoring to assess ventricular ectopic frequency. Circulation, 58, 408.

MUHIDDIN, K.A., NATHAN, A.W., HELLESTRAND, K.J., BANIM, S.O. \& CAMM, A.J. (1982). Ventricular tachycardia associated with flecainide. Lancet. ii, 1220.

MUHIDDIN, K.A. (1983). Some clinical pharmacological studies on flecainide, a new antiarrhythmic drug. Ph.D. thesis, University of London, $169 \mathrm{pp}$.

NATHAN, A.W., HELLESTRAND, K.J., BEXTON, R.S., BANIM, S.O., SPURRELL, R.A.J. \& CAMM, A.J. (1983). The proarrhythmic effects of a new antiarrhythmic agent flecainide acetate. American Heart Journal, 107, 222.

SALERNO, D.M., HODGES, M., GRANRUD, G. \& SHARKEY, P. (1983). Comparison of flecainide with quinidine for suppression of chronic stable ventricular ectopic depolarizations. A double-blind randomized study in ambulatory outpatients. Annals of Internal Medicine, 98, 455.

SCHMID, J.R., SEEBACK, B.D., HENRIE, C.L., BANITT, E.H. \& KVAM, D.C. (1975). Some antiarrhythmic actions of a new compound, R-818, in dogs and mice. Federation Proceedings, 34, 775.

SOMANI, P. (1980). Antiarrhythmic effects of flecainide. Clinical Pharmacology and Therapeutics, 27, 464.

VERDOUW, P.D., DECKERS, J.W. \& CONARD, G.J. (1979). Antiarrhythmic and haemodynamic actions of flecainide acetate (R-818) in the ischemic porcine heart. Journal of Cardiovascular Pharmacology, 1, 473.

WINKLE, R.A., MASON, J.W., GRIFFIN, J.C. \& ROSS, D. (1981). Malignant ventricular tachyarrhythmias associated with the use of encainide. American Heart Journal, 102, 857 . 